\title{
Introspections and Suggestions on the Amount Fixing of Administrative Penalty for Environmental Pollution
}

\author{
Xiaohong Zheng \\ Law school Southwest University,Chongqing, China,400715 \\ Email: yshnj1s2010@163.com
}

Received 2013

\begin{abstract}
Environmental pollution has seriously damaged the health of mankind and the development of future generations. Because pollution damages are irreversible, taking effective measures to prevent contamination accidents is the primary task for administrative penalty on environmental pollution. However, the specific amount of such penalty is a little bit on the low side, and the standard for fixing the penalty is not rational somewhat. As a result, the original functions and purpose of administrative penalty on environmental pollution cannot be fully achieved. By comparing and using for reference related systems at home and abroad, this paper advances the drawbacks and suggestions for the amount fixing of China's administrative penalty on environmental pollution in the hope of supplying theoretical basis for the improvement of China's administrative penalty mechanism on environmental pollution.
\end{abstract}

Keywords: Environment; Administrative Penalty; Amount Fixing

\section{Introduction}

Over the past twenty years, China has experienced the period of high environmental risks. According to statistics, the direct economic losses merely brought about by environmental pollution each year amount to RMB 120 billion Yuan. Besides, environmental pollution will result in potential and irreversible damages to human health. As an important measure for environment-oriented law enforcement, the administrative penalty mechanism on environmental pollution made some achievements in the past, but it is rather weak and seriously lags behind in its performance with the increasingly serious environmental pollutions. The most typical case was the ConocoPhillips's oil spillage accident in June 2011: the polluted sea area covered 6,200 square kilometers, which led to a direct economic loss of more than RMB 100 million Yuan, which seriously damaged the public health. However, the corresponding administrative penalty was only RMB 200,000 Yuan, which was only a minuscule amount for a company with an asset of tens of billions of USD like ConocoPhillips, and could not truly show its warning effect to the violator. Another case is the American's Mexico Gulf oil leakage accident in 2010: the responsible party was imposed a fine of 1.256 billion USD, and was required to establish a foundation of 20 billion USD as well as make a subsequent payment of 3.269 billion USD for solving the accident. The responsible party for an oil spillage accident in November 2011 in Brazil was promptly imposed a heavy fine of 50 million BRL (equivalent to 28 million USD). The greatly different results between China and foreign countries in handling environmental pollution accidents push us to re-examine the design of China's administrative penalty system on environmental pollution and to re-think of the fixing on the amounts of such penalties so as to find out the crux of the problem.

\section{Related Legal Provisions on Administrative Penalty for Environmental Pollution in China}

Presently, China has been implementing the Law of the People's Republic of China on Environmental Protection that is adopted in 1989. Article 35 of the law entitles the competent administrative department of environmental protection to give warning or impose a fine to "such behaviors as refusing the spot inspection by the competent administrative department of environmental protection or other departments that exercise administration and supervision on environment according to law, or resorting to deception during the inspection", that is, the competent administrative department of environmental protection was granted the power of imposing administrative penalty directly. The Law of the People's Republic of China on Administrative Penalty implemented on Oct. 1, 1996 applies the principle of "moderate punishment on fault," such as Article 4, which stipulates "the administrative penalty shall be fixed and implemented on the basis of fact and shall be moderate to the act, nature and 
circumstances of the offence as well as to the damage to the society," In Article 51, it is stipulated that the faulty party shall, if failing to pay the penalty over due time, be imposed a fine of $3 \%$ of the penalty for each overdue day; in the Article 73 of the Law of the People's Republic of China on Marine Environment Protection implemented on April 1, 2000, it is stipulated that the faulty party who discharges the pollutant that is forbidden to discharge to the sea area by this law shall be imposed a fine amounting to no less than RMB 30,000 Yuan but no more than RMB 200,000 Yuan," which is a provision on maximum punishment for the marine environmental pollution in China; the Article 75 of the new Law of the People's Republic of China on Water Pollution Prevention and Control (revision in 2008) stipulates that "the people's government at county level or above shall order the party who sets up sewage outlet within the protective area of the drinking water source to dismantle such outlet within the limited time and impose a fine no less than RMB 100,000 Yuan but no more than RMB 500,000 Yuan, provided the responsible party fails to dismantle such outlet in the due time, the outlet will be dismantled forcefully and the expenses arising from such forceful dismantling shall be borne by the responsible party who is also imposed a fine of no less than RMB 500,000 Yuan but no more than RMB 1 million Yuan or the responsible party is even ordered to stop production for rectification," which is a provision on maximum punishment for the environmental pollution in China and is strictly limited to apply within protective area of the "drinking water source," as shown to us, the amount of administrative penalty on environmental protection is on increase in China. Prior to September 2000, China adopts the principle of collecting charges for the sewage drainage exceeding permits and such drainage was deemed as the legal act after the party pay the drainage fee," but the new Law of the People's Republic of China on Prevention and Control of Atmospheric Pollution (revision in 2000) adopts the principle that "the party exceeds the sewage drainage permit is required to make harness within limited time and is imposed a fine," and that "the sewage drainage exceeding the permit is deemed as an illegal act;", In the aspect of laws on prevention and control of noise pollution, the measure of "collecting the drainage fee for the sewage drainage exceeding the permit" is still applied. The inconsistency between the laws and norms brings inconvenience in implementing the pollution penalty system in the practice; and the extents to which the penalty is determined are also different in particular situations as they are determined by different persons or in different areas. It is stipulated in the Article 9 in the new Law of the People's Republic of China on Water Pollution Prevention and Control (revision in 2008) that "the water pollutants discharged shall not exceed the national or local standards on water pollutant drainage and the limited index of the total amount of the key water pollutants discharged." China has moved a great step forward in the aspect of environmental protection by controlling the total amount of the pollutants.

In accordance with the Constitution Law, the Law of the People's Republic of China on Environmental Protection and the relevant provisions of laws on protection, prevention and control of natural resources, the objective of the environmental protection law and the ultimate goal of the administrative penalty on environmental pollution is to "safeguard the health of mankind and promote the sustainable development of economy and society." The $18^{\text {th }} \mathrm{CPC}$ national congress that was concluded not long before has blueprinted the future development of China, which will put the ecological civilization construction in priority in China's modernization. The annual meeting of China Council for International Cooperation on Environment and Development (CCICED) that was opened on December 12, 2012 has the theme of "regional balance and green development." Therefore, as one of the most common and most effective measures for environmental protection, the administrative penalty on environmental pollution is to safeguard the health of the mankind, protect the environment and achieve the sustainable economic and social development in the end.

\section{Introduction \& Analysis on Internationally Advanced experience of Administrative Penalty on Environment Pollution}

\subsection{US System of Administrative Penalty on Environmental Pollution}

When speaking of the legislation on administrative penalty for the environmental pollution, the US is the first country to be introduced as its administrative legislation on environment is in the pioneering rank in the world. At present, the commonly used system of penalty by day in the world was first implemented in the US and it is the most characteristic of the US administrative penalty; what's more, the amount of the US's administrative penalty is usually enormous figure, it is natural that the violator will evaluate the serious consequences arising from the violation act through the cost-benefit analysis in such pressurized condition, and thus greatly reducing the intentions to violate the laws.

The US has worked out the National Environmental Policy Act in 1969, which is one of the earliest basic environmental laws in the world. The country has passed the Clean Air Act in 1970, the Clean Water Act in 1972, etc. As the chemical pollution accident in the Love Canal was revealed, the US Congress passed the Comprehensive Environmental Response, Compensation, and Liability Act (CERCLA) [1] in 1980 under the pressure of 
the public. The federate administrative authority in charge of environment is the United States Environmental Protection Agency (USEPA), and deterrent force of US's administrative penalty on environmental pollution mainly arises from the penalty type and fine amount. The USEPA has the power of enforcement on civil legislations in which the judicial organ participates, and its penalty is at high degree. In the aspect of fine amount, the US has stipulated the upper limit on the maximum fine amount and adopts the "penalty by day" system in practice, that is, the limit to the daily penalty is stipulated in dynamic state, i.e., the amount of daily penalty on a violation act is limited and varies with time, the longer the time passed, the more the penalty amount was.

It is indicated in the Administrative Penalty Policy formulated by EPA that "permitting the violators to earn benefit from the violation act will put the legalists in the unfavorable position, and thus making a penalty on them, therefore, the main economic benefits arising from the illegal act shall be collected via the administrative penalty." [2] The first step to determine the amount of the administrative penalty is to determine the cardinal number of the fine mainly on the basis of the benefits obtained from the illegal act. Unless otherwise stipulated, the penalty amount shall not be less than the benefits obtained from the illegal act [3]. For example, EPA requires the enforcement official to give the reason in the files provided the penalty amount is less than the illegal benefits; the second step is to adjust the coefficient, to ensure the violator reluctant to repeat the violation act, and the potential violator to cancel the intention of violation due to the huge penalty, it is necessary to make adjustment on the basis of the cardinal number. As is shown by the court in the case of complaint of SPIRG against SPIRG v. Monsanto Co. that "it is not sufficient to prevent the violator or potential violator from stopping its illegal act under the condition that the penalty amount is equivalent to the economic returns of the violator, it is necessary to add the extra fine to the penalty amount to achieve the punishment effect.

\subsection{Legal System of Brazil on Environment}

The content and system of the Brazilian environmental legislation have been relatively matured, and some scholars think it is one of the most advanced legal systems on environment in the world. However, like most of developing countries, the environmental law is in poor enforcement in Brazil. The Brazilian government has issued the National Environmental Policy Act on August 31,1981 , which is a milestone in the Brazilian legislation; the country has issued another epoch-making law of Environmental Offence Act in 1998, which features the definitive provisions on fines, it is stipulated in the Article
75 that the maximum fine imposed on the violator may reach 50 million BRL. The key that the Brazilian administrative authority can make a penalty in no time is that the Brazilian judicial system has granted the strong power to the supervision organs, which intervenes widely in the environmental protection and forms the unique background for the enforcement of supervision organs. In addition, according to the environmental penalty system of Brazil, the administrative penalty may be determined prior to the penalties of other kind in the case of the serious violation against the environment administration. The Brazilian environmental legislation, with the detailed provisions and complete system, forms the relatively complete and reciprocally complementary legal system on environmental protection with the Constitution Law at the core, which is a system that may rival with the system of the developed countries because Brazil selects a law enforcement road different from that of the other countries in Latin America, in particular, the Brazilian legal system on environment has introduced and referenced the German environment law and the US environment law, which are the most advanced laws in the world.[4]

The design of penalty system on environmental pollution in other countries may provide reference to China to complete our administrative penalty system against environmental pollution. The above-mentioned introduction tells us that the relatively large amount of administrative penalty on environmental pollution has been an international trend, which has the following in common: First, intensify the penalty force and enforcement; second, the penalty procedure is dominated by the administrative authority and participated by the judicial organ; the penalty amount is determined by the coefficient calculation based on the cardinal number. Compared with the practical experience abroad, the introspection on the drawbacks and the system design of penalty amount fixing has called our concerns.

\section{Introspections on the Amount Fixing of Administrative Penalty on Environmental Pollution}

\subsection{Amount Fixing Mode of Administrative Penalty}

"Numerical Interval" mode is mostly applied to the penalty amount fixing in China, and its upper limit is still low to achieve the ideal of justice that "making the illegal cost considerably higher than compliance", which may result in a higher compliance cost and a lower illegal cost. "Multiple Penalty" mode is adopted in Article 73 of Law of the People's Republic of China on Prevention and Control of Water Pollution, which stipulates that the faulty party who mishandled the treatment facilities 
for water pollutants shall be imposed a fine of more than doubled and not more than three time payable pollutant discharge fee. However, due to the severe low payment base, the penalty, even triple pollutant discharge fee, is still on the low side. Generally speaking, penalty amount shall be sharply increased and make sure an easy and accessible calculation mode anyway.

\subsection{Limitation of the Principle of "Moderate Punishment on Fault"}

Such principle mainly applies to those incurred fault or loss. However, many faults or losses needed to be handled are not incurred during the environmental administrative enforcement, for instance, the river water has been polluted but such pollution is not impaired anyone yet. Due to the lack of specific data of such fault or loss, the principle of "moderate punishment on fault" may not be helpful for related administrative department to determine the amount of penalty imposed on violator. Apart from the said principle of "moderate punishment on fault", the Law of the People's Republic of China on Administrative Penalty has not given any detailed specification on the amount of administrative penalty. The abovementioned laws and regulations specify quite different penalty amounts for different (but similar) illegal activities as well as fix a broader interval (more than RMB 10,000 Yuan but not more than RMB 100,000 Yuan) on the penalty amount for single illegal activity. As a result, penalty will be imposed at the discretion of the law enforcement officials, which may lead to arbitrary law enforcement.

\subsection{Afterwards Indemnity Functions}

The Law of the People's Republic of China on Administrative Penalty places an over-emphasis on maintaining legal sanctity by penalty and reflects the responsibility to the State from administrative counterpart, but neglects the indemnity for victims. In the United States, penalty system has functions of pre-restraint and post-punishment as well as indemnity functions, which is to compensate for the loss of victims and social public interests.

Study on the penalty system design of other countries may provide salutary reference and lesson for China to perfect our administrative penalty system. We shall not simply copy or imitate foreign administrative penalty system but make a thorough investigation on how to better improve it considering China's national conditions when we use it for reference. By this, it is expected that such reference will improve and optimize the administrative penalty system on the whole to produce the best possible value and effect. Therefore, through comparison and analysis on the common practice of current international administrative penalty system, the writer puts for- ward following suggestions:

\section{Suggestions on Improving the Amount Fixing of Administrative Penalty on Environmental Pollution}

\subsection{Establish New Concept on Environmental Protection Based on Sociology and Ecology Prevention of Environmental Protection}

Administrative penalty on environmental pollution shall have functions of prevention and restraint beforehand as well as post-punishment and deterrent. Such practice as pollution prior to control and damage prior to rehabilitation would inevitably duplicate the unsustainable development mode on economy and society. [5] Administrative penalty on environmental pollution has a theoretical prerequisite that the government shall represent the society and be commissioned to make an overall plan and to rationally eliminate and diminish violations of laws and regulations that impair the society. The ultimate solution is to prevent the problem from happening. Similarly, the most effective solution to eliminate pollution is to keep it from occurring. [6] Use "Society Standard" instead of "National Standard" to fully achieve the tenet of "Law enforcement for the people" into specific administrative penalty fixing on environmental pollution. Make an analysis on legal issues by using economic theory and method and adopt proper penalty amount fixing mode is to solve the problem with the minimum legal resource, i.e. to take economic efficiency as the goal and evaluation criterion of the laws and to make legislation, enforcement and justice advantageous for the social wealth increment.

\subsection{Use "The Hand Formula" for Penalty Amount Fixing}

"The Hand Formula" was formally put forward in 1947 by Learned Hand, the United States federal judge at the case of the United States' litigation of Carol Towing Company. [7] This Formula is of heuristic and connotative view of society. In a sense, it integrates the plaintiff and the defendant to make a "unified settlement", and then regards the society as a whole, which has a coincident goal with the administrative penalty on environmental pollution. Therefore, such administrative penalty fixed by this formula should be able to effectively impel parties to take adequate and rational preventive action to avoid related impairs.

\subsection{Carry Out "Fined per Diem" Rule}

Wang Canfa said that the stipulated maximum fine of RMB 3 million Yuan is not necessary when amending the Law of the People's Republic of China on Prevention 
and Control of Water Pollution and that the fine should be imposed by the day no matter how much the fine is. For example, Du Pont Company was imposed a fine of 25 thousand USD per day and ultimately 310 million USD for Teflon that may impair people's health from the day it got to know such risk until it halted sales, and Du Pont Company was deterred to break the law again. Friends of Nature, a non-governmental environmental organization has held a seminar in regard to amendment of environmental protection law and the experts participating in the seminar believed that "Fined per diem" rule should be regarded as core content in the published amendment of environmental protection law. Liang Xiaoyan, the executive director of Friends of Nature suggested supplementing the Law with "Fined per diem" rule that worked in the practice on environmental protection in many other countries around the world.

\subsection{Implement Environmental Liability Insurance System and Set up Damage Compensation Fund}

Environmental liability insurance system and damage compensation fund can be regarded as two compensation modes for post-punishment of administrative penalty on environmental pollution. Such modes can be put into trial implementation in accordance with the specific circumstance in China and both of them pertain to the category of environmental tort remedy socialization. This insurance and compensation system has been maturely used in the US, Germany and Sweden. Theoretical foundation for environmental tort remedy socialization mainly originates from social responsibility theory, balance of interests theory and economic externality theory. Speaking of Superfund Law, it indeed works in the abovementioned Gulf of Mexico oil spill. China may use for reference to share risks in a socialized way and to keep polluting enterprises from bankruptcy that may influence economic development. This is of importance for such developing countries as China.

\section{REFERENCES}

[1] J. Wang, "Science of Environmental Law," Peking University Press, Beijing, 2006.

[2] Policy on Civil Penalties, EPA General Enforcement Policy\#GM - 21, recodified as PT. 1-1(Feb.16, 1984), P. 3.

[3] Atlantic States Legal Found. V. Tyson Foods, Ine., 897 F.2d 1 128, 1 141(1 1 Ih Cir.1990).

[4] C. Fan, "Analysis and Assessment on Brazilian Legal System on Environmental Protection," Northern Legal Science, Vol. 5, No. 2, 2011.

[5] D. P. Han, "Courses on Environmental Protection Law" Law Press China, 2003.

[6] J. R. Ye, "Environmental Policy and Law," China University of Political Science and Law Press, Beijing, 2003.

[7] Z. Y. Wei, "Civil Law," Peking University Press, Beijing, July. 